\title{
Article
}

\section{An Exploration of the Experiences of Elite Youth Footballers: The Impact of Organisational Culture}

Champ, Francesca Mary, Nesti, Mark S., Ronkainen, Noora J., Tod, David A. and Littlewood, Martin A.

Available at http://clok.uclan.ac.uk/23940/

Champ, Francesca Mary ORCID: 0000-0002-9319-8292, Nesti, Mark S., Ronkainen, Noora J., Tod, David A. and Littlewood, Martin A. (2018) An Exploration of the Experiences of Elite Youth Footballers: The Impact of Organisational Culture. Journal of Applied Sport Psychology, 32 (2). pp. 146167. ISSN 1041-3200

It is advisable to refer to the publisher's version if you intend to cite from the work. http://dx.doi.org/10.1080/10413200.2018.1514429

For more information about UCLan's research in this area go to http://www.uclan.ac.uk/researchgroups/ and search for <name of research Group>.

For information about Research generally at UCLan please go to http://www.uclan.ac.uk/research/

All outputs in CLoK are protected by Intellectual Property Rights law, including Copyright law. Copyright, IPR and Moral Rights for the works on this site are retained by the individual authors and/or other copyright owners. Terms and conditions for use of this material are defined in the policies page. 


\section{An Exploration of the Experiences of Elite Youth Footballers: The Impact of Organisational Culture}

\section{Francesca M. Champ, Mark S. Nesti, Noora J. Ronkainen, David A. Tod \&} Martin A. Littlewood

To cite this article: Francesca M. Champ, Mark S. Nesti, Noora J. Ronkainen, David A. Tod \& Martin A. Littlewood (2018): An Exploration of the Experiences of Elite Youth Footballers: The Impact of Organisational Culture, Journal of Applied Sport Psychology, DOI: 10.1080/10413200.2018.1514429

To link to this article: https://doi.org/10.1080/10413200.2018.1514429

Accepted author version posted online: 30 Aug 2018.

Submit your article to this journal 7

Џ Article views: 5

View Crossmark data ¿ 


\section{An Exploration of the Experiences of Elite Youth Footballers:}

\section{The Impact of Organisational Culture}

Francesca M. Champ

University of Central Lancashire, Liverpool John Moores University

Mark S. Nesti

Liverpool John Moores University

Noora J. Ronkainen

Liverpool John Moores University

David A. Tod

Liverpool John Moores University

Martin A. Littlewood

Liverpool John Moores University 


\begin{abstract}
The present study explored how the organisational cultural experiences of elite youth footballers shaped their identity development and behaviour. The first author occupied the position of sport psychology practitioner-researcher within one professional football club over a 3-year duration. Traditional ethnographic research methods were employed, including; observations, field notes, reflections, and informal interviews. A Cultural Sport Psychology (CSP) perspective on identity as a social construction, and research on the cultural characteristics of professional football were used as frameworks to make sense of the data. Despite the introduction of the Elite Player Performance Plan (EPPP) in 2012, the traditional masculine culture of professional football dominated the studied club. Creative non-fiction vignettes revealed that youth players were encouraged to develop their self-stories focused on a single-minded dedication to professional football. The limited identity-related resources offered at both club, and cultural level is detrimental for players in terms of their well-being, and long term psychological development. From the results of this study, we suggest that future sports psychology practice within professional football may best be delivered at an organisational level. However, in order for a sport psychologist to be effective in this role they must develop an understanding of the sub-cultural features and characteristics of the organisation. In line with this, there would be great value in introducing a focus on organisational culture within sport psychology professional training and education routes.
\end{abstract}

Keywords: cultural sport psychology, identity, psychological development, youth, football 
An Exploration of the Experiences of Elite Youth Footballers:

The Impact of Organisational Culture

A number of researchers (e.g., Cushion \& Jones, 2006; Kelly \& Waddington, 2006; Nesti, 2010; Parker, 1995; Roderick, 2006) have highlighted the highly competitive and masculine culture of professional football, and its potential to influence the experiences of players who operate within this social context. In this paper, we define organisational culture as a 'glue' (Dowling, 1993) that binds together organisational members, history, and material artefacts (e.g. logo, artefacts), and brings them towards a common purpose (Hatch \& Schultz, 1997). The dominance of hegemonic constructions of masculinity within the organisational culture of professional football (Parker, 1995; Roderick, 2006) is demonstrated by players' displays of rigid hierarchical narratives of what constitutes a "real man" in terms of who can withstand the most physical and emotional pain, and who can best keep their personal feelings to themselves (Smith \& Sparkes, 2009).

Sport psychology scholars have noted that these environmental characteristics might not be conducive to the healthy psychological development and identity formation of youth players as they progress in their developmental pathway within a professional football club (e.g., Knapp, 2014; Mitchell, Nesti, Richardson, Midgley, Eubank, \& Littlewood, 2014). Each year, over 1000 boys are contracted to a professional football academy between the ages of 9 and 16 in England. In spite of this, very few boys will succeed in ever attaining a professional contract. In fact, Anderson and Miller (2011) stated that only $10 \%$ of academy players who receive a youth scholarship aged 16 will be successful in attaining a professional contract at the age of 18. Despite such low statistical chances of success, most of these boys are constructing their lives solely within professional football (Brown \& Potrac, 2009). Such foreclosure at this formative time when adolescents should be engaging in developmental 
tasks of exploring their identities and possibilities in life has the potential to bring longstanding consequences to their development and well-being. A number of studies exploring athlete identity and career transitions have showcased the processes of identity narrowing, and its negative consequences for athlete well-being if they get deselected or injured (Bruner, Munroe-Chandler, \& Spink, 2008; Gordon \& Lavallee, 2011; Stambulova, Alfermann, Statler \& Cote, 2009; Wylleman, Alfermann, \& Lavallee, 2004).

Sports psychology researchers have used traditional research methods (e.g., semistructured interviews, questionnaires) to explore some of the psychological challenges that young players may face as they progress within a football academy (Mills, Butt, Maynard, \& Harwood, 2012; Reeves, Nicholls, \& McKenna, 2009). Although these have certain merits (e.g. interactive, allow for probing, controlled answering order (Weiss, 1994)), and have been useful in identifying a range of potential stressors, researchers have not yet explored the impact of the professional football culture on the psychological development of youth players from the position of an insider (Maitland et al., 2015). Insider research is conducted within an organisation where the researcher is also a member (Greene, 2014), and can be beneficial in deepening our understanding of the experiential realities of youth players embedded in these environments by allowing us to "understand the cognitive, emotional and/or psychological precepts of participants as well as possess a more profound knowledge of the historical and practical happenings of the field" (Chavez, 2008, p.481).

To summarise, the psychological development and identity formation of elite youth footballers has largely been unexplored over a longitudinal time frame. Furthermore, there is limited research from sports psychology practitioners who have actually explored this social context from the position of an insider (Nesti, 2010). The longitudinal observation of the participating organisation in their natural setting will allow for a deeper understanding of key stakeholders natural actions and behaviours (Patton, 2005). 
The current paper addresses this specific gap in the literature, and employed insider ethnographic research principles across three footballing seasons to attain a more holistic understanding of the challenges faced by youth footballers. Unlike cross-sectional studies, and one off interviews, this study has the potential to provide insight into the processes of identity development over a long period of time (Atkinson \& Hammersley, 1994). The indepth analysis of extensive fieldwork can allow for developing a deeper understanding of the daily experiences of youth players and their potential implications for identity development. This kind of holistic understanding of players lived realities is necessary for developing culturally informed and effective applied sport psychology services. Secondly, it will enhance sports psychology practitioners awareness of the unique socio-cultural challenges that players must successfully navigate if they are to 'make it' as a professional footballer. Our aim is to address the following research objectives:

1. To examine the organisational cultural experiences of elite youth footballers as they progress within one professional football club over three full seasons

2. To gain an understanding of how elite youth footballers' experiences within the professional football culture influences their identity development and behaviour

\section{Theoretical approach}

One way to extend understandings of youth player identity development within professional football is to use a cultural sport psychology (CSP) lens (Ryba \& Wright, 2010). In the last decade, sport psychology researchers have focussed attention onto the topic of culture with the aim of developing a more contextualised understanding of marginalised voices and identities (see McGannon, Curtin, Schinke, \& Schweinbenz, 2012). More specifically, CSP highlights the self-identity as simultaneously social and cultural, rather than reducing them to isolated mechanisms within the mind, as with mainstream approaches in sport psychology 
(see McGannon \& Smith, 2015). Grounded in social constructionism, CSP centralises language, narrative, and discourse in the construction of self-identities (Douglas \& Carless, 2009; McGannon \& Smith, 2015). In this paper, we define identity as particular form of social representation that represents the relationship between the individual and others (Chryssochoou, 2003). Using cultural sport psychology allows us to advocate for an exploration of youth player identity as a socio-cultural construction (McGannon et al., 2012). Within this framework, youth player identity is regarded as the product of individual, social, and cultural narratives intertwined (McGannon et al., 2012). Conceptualising youth player identity in this way allows for novel insights into the influence of the professional football culture on player identity and behaviour.

\section{Method}

In the last decade, ethnography has been increasingly used as a research method in sport (Cushion \& Jones, 2006; DeRond, 2008). We adopted this approach because it was the most appropriate method to answer the research questions. Tedlock (2000) suggested that "by entering into close and relatively prolonged interactions with people... in their everyday lives, ethnographers can better understand the beliefs, motivations, and behaviours of their subjects than they can by using any other approach" (p.456). Closely aligned with this is the notion that ethnography is inductive, accepts that there are multiple ways of both seeing and interpreting things, and acknowledges the influence of the researcher on the research process (Atkinson \& Hammersley, 1994). In this way, ethnography aligns with the cultural tenets of CSP in advocating a view of knowledge as situated and theory-laden, and open to alternative interpretations (McGannon \& Smith, 2015). The use of ethnography in this study by an applied practitioner provides an emic view (i.e., that of a cultural insider) on the experiences of elite youth footballers, and opens up new avenues for consideration (Krane \& Baird, 2005). More specifically, I (first author) used ethnographic methods to contextualise a series 
of highly personalised stories, and convey lived experiences relating to the tellers' personal and cultural understandings (Richardson, 2000). In the following sections, the plural (we) is used to signify the research team whereas the singular form (I) relates to the first author. The aim of using first person voice is to evoke an emotional response from the reader by creating an intimate connection between themselves and the authors.

\section{Philosophical underpinning}

This research is situated within CSP genre and thus within a social constructionist, interpretive paradigm. Within a social constructionist perspective (Atkinson \& Hammersley, 1994), meaning is derived from interpretation, and knowledge is only considered significant in so far as it is meaningful (Smith \& McGannon, 2017). Furthermore, the methodological perspective was underpinned by a relativist ontology (a belief that there are multiple social realities), a subjectivist epistemology (knowledge is created through social interaction) and a naturalistic set of methodological procedures (data collection occurs in the world of the participants) (Cornbleth, 1990).

\section{Biographical positioning}

I did not purport to approach the field setting as a blank slate, or from an objective position, instead I brought a number of identities to the field. More specifically, these 'selves' were a researcher based self, a self who was a sport psychology practitioner, a self who was a female, a student, an early career practitioner, and a passionate football fan. Furthermore, I come from a footballing family; some of whom were successful in having a professional football career, and others fell at the final hurdle before attaining a professional contract. I acknowledge that these identities will have influenced what I observed within the professional football club, how I felt about what I experienced in the club, and what I have reported in this study (Cornbleth, 1990). For example, observing the long-term impact of the 
professional football culture on the psychological development of close family members left me with a number of pre-determined beliefs and ideas before I entered the organisation (e.g. ruthless approach to players deemed not good enough). Because of this, I was drawn to those individuals who I observed to be isolated from their teammates, and categorised by staff as 'psychologically weak'.

\section{Participants}

For the purposes of the study, we have chosen to represent the participating organisation using the pseudonym 'Burrington City FC'. Burrington City FC is a medium sized club that has been in existence for over 100 years. In excess of 50 support staff (aged 22-60) are contracted to work with academy players in the U9-U23 age groups occupying a range of roles (e.g. coaching staff, education team, scouting team). I interacted with a number of these individuals on a daily basis, for example the coaching department, the department of science and medicine, and the education officers. However, other than the club chef, I was the only female employed by Burrington City FC based at the training ground. Like many other clubs, Burrington City FC has seen better days financially and remains reliant on the successful development, and subsequent sale of academy players to survive. Despite this, the club is still one of the 92 UK teams currently in the English Football League, and takes great pride in the academy set up and its record of producing players that go on to play at the highest professional level.

\section{Developing the ethnography}

Once access is gained, ethnography enables the researcher to embed himself or herself within the cultural practice as an insider, and observe the daily working practices of an organisation over a prolonged period of time (Atkinson \& Hammersley, 1994). This engagement often lasts for several months, but can take place over a number of years (Krane 
\& Baird, 2005). In this study, I was familiar with Burrington City FC prior to taking on the role as practitioner-researcher. More specifically, I was granted access for the completion of an MSc sport psychology placement in the season beforehand. The successful completion of this placement resulted in me being offered a dual role as a practitioner-researcher embedded within the culture of study for a further 3 years. More specifically, I was responsible for the delivery of psychological support to academy footballers and support staff within one professional football club 3 days per week. Methods of support included; individual support sessions, group workshops, stakeholder education, and pitch based delivery. My philosophy of practice was embedded within a holistic humanistic consulting approach (Friesen \& Orlick, 2010). I felt that this approach was appropriate for the individuals that I was working with, as they ranged from 12 to 23 years of age, and many were yet to attain a senior professional contract. Therefore, these young athletes were in a vulnerable position in that their youth contract could have been terminated at any time, and their affiliation with the club would in that case be terminated. I felt that adopting a humanistic consulting philosophy over a longitudinal period helped me to develop strong and trusting relationships with these youth players. My role within the organisation changed and progressed over time. The organisational chaos (Galbraith, 2004) experienced by the organisation as a function of staff turnover meant that I was required to deliver aspects of organisational psychology. For example, I was required to manage delicate and challenging relationships between different stakeholders, and departments.

Occupying a dual role as a practitioner-researcher was a key feature of the research. Krane and Baird (2005) highlighted the benefits of a research method where the researcher is embedded within an organisation. They suggested that doing ethnography allows us to truly hear the voices of coaches, athletes, and practitioners, and therefore will deepen our understanding of their experiences. However, the challenge for the researcher here is how to 
make sense of, and create meaning in this world. Wittgenstein (1953) believed that we cannot learn a language or understand how a social group communicates unless we take part in the form of life in which the language is used. Therefore, by spending a prolonged period of time within an organisation the researcher becomes "saturated with first-hand knowledge of the setting" (Morrill \& Fine, 1997, p.435). This has particular relevance for the present research given the culturally endemic feature of language and banter in professional football, which often outsiders may fail to understand or recognise (Parker, 1995).

\section{Data Collection}

I collected the data using a variety of methods often employed in ethnographic research including; observations, reflections, informal interviews, and field notes (Kahan, 1999). I observed players and staff within the academy set up of Burrington City FC from September 2014 to May 2017; during this time, three full playing seasons and three preseasons were completed. In total, I spent over 3000 hours within the professional football club, and accumulated over 300 pages of field notes within the reflective log. The purpose of the observations was to develop an understanding of the setting and culture, interactions and activities that took place within the setting, the people who took part in the activities, and the meaning of what was observed from the perspective of those who were being observed (Lofland \& Lofland, 1984). Initially, the data collection phase had a broad focus on deepening our knowledge and understanding of the world that I was embedded within. However, as the doctoral project progressed it became clear that the professional football culture had a significant impact on the development and behaviour of individuals within the organisation, consequently the impact of this on the psychological development of players became a focal point. 
Based on the events that I had observed within Burrington City FC, I completed field notes in a reflective journal after each occasion I was present in the club (Atkinson \& Hammersley, 1994). We chose not use a separate research log and reflective journal, rather we used the reflective journal to document both the field notes, and personal reflections (Ortlipp, 2008). The purpose of combining both the field notes, and the researcher's reflections was to use the field notes to facilitate critical reflection (Maharaj, 2016). By having these situated together, I could return to particular events, and reflect on the continued impact. In line with Bogdan and Biklen (1982) my reflexive journal was both descriptive, and reflective. The field notes were descriptive, dated, and recorded key details. Following each field note entry, I added my own reflections using the connotation RC (Reflective Comments); these contained my interpretations of the day's events from the perspective of both a sport psychology practitioner, and a doctoral researcher. Engaging in this reflective process forced me to think about each aspect of the day, and to explore how I understood their meaning. Furthermore, taking the time to write about these events further engrained them into my memory, and provided an initial outlet for recording impressions and ideas before a more systematic analysis.

\section{Data analysis and Representation}

The first step of the data analysis was to extract the data documented in the field notes and the reflective log. From the raw data, I conducted a social constructionist thematic analysis (see Braun \& Clarke, 2006). The initial grouping of the themes was inductive (Javadi \& Zarea, 2016). More specifically, we used a subjective judgement of those events that related to the impact of the professional football culture on the experiences of youth players (Schinke, Papaioannou, \& Shack, 2016). These events were plotted chronologically on a timeline that represented the 3-year duration of the study (Kolar et al., 2015). The purpose of the timeline was to create a visual representation of the data, and allow us to more clearly 
depict patterns in the data. Sheridan, Chamberlain, and Dupuis (2011) suggested that timelines have particular value for narrative forms of research in documenting, recording, and deepening our understanding of our participant's experiences over time. In addition to this, the timeline was used as a method to identify evolutions in the research over the 3 -year study duration. Following this, I then discussed the themes with my research team members, and re-read the notes pertaining to each event to further engrain the data in my memory. Based on critical discussion, I added notes to the timeline with the aim of identifying parallels and recurring events. We then used a CSP perspective on identity as a social construction (McGannon \& Smith, 2015), and research on the cultural characteristics of professional football as frameworks to make sense of the data.

In the final step, we developed a series of creative vignettes to illustrate key issues in relation to identity development in youth players. The purpose of creative non-fiction is not to make up the setting and events, rather to describe a situation as accurately as possible using the techniques of fictional writing (e.g. composite characters, tone shifts) to create an evocative and thought provoking text. For example, in our study we make use of composite characters, vernacular language, tone shifts, allusions, and metaphors. Blodgett et al. (2015) advocated the use of vignettes as a research strategy that supports cultural praxis, that is research that aims to increase cross-cultural understandings and deliver culturally informed services (Schinke et al., 2012, p.34). The content of the ethnographic creative non-fiction is grounded in the analysis of over 3000 hours of observation, and dialogic exchanges with key stakeholders (e.g. players and staff), which demonstrates significant embeddedness in the study environment. We represented the research findings in the form of three stories, these were refined as the writing developed to ensure that they faithfully represented the themes that had been identified (Smith, 2013). In addition to this, we used direct quotations from stakeholders that were documented in the reflective log, but the manner in which the stories 
are presented was chosen to best represent the themes, plots, and theoretical points generated from the data analysis (Smith, 2013). The vignettes that are presented in the following section each encompass the narrative of a different individual within Burrington City FC. The aim of using creative non-fiction as a method of data representation was to deepen our understanding of the holistic challenges faced by elite youth footballers in the professional football culture.

\section{Research Quality and Methodological Rigour}

Our approach to research quality was guided by Smith and McGannon (2017) who argued that research quality is ground in member reflections, critical dialogue, and its contribution to knowledge. More specifically, the researcher engaged in member reflections throughout the research project. Member reflections involved sharing the research findings, and engaging in dialogue with the members of the professional football club (Tracy, 2010) on appropriate occasions during data collection (e.g. the end of each season). The aim of this was to explore gaps in the results, and similarities shared concerning interpretations of the findings (Schinke et al., 2016). These member reflections enhanced the credibility of the research by offering an opportunity for collaboration, and reflexive elaboration, and allowed us (research team) to establish a greater understanding of the meaning that participants attached to events. In addition to this, the member reflections informed the data analysis as they provided dialogue to add further interpretation to the events that I had observed. This is reflected in the vignettes, where direct quotations from individuals at the centre of the events are presented to demonstrate their thoughts and feelings. Secondly, I engaged in a process of dialogue with 'critical friends' (Morrow, 2005) following each season of my involvement with Burrington City FC. I presented the raw data that had been collected during the season, and my interpretations of this data. Following each presentation, we had a round table discussion, here research team members challenged some of my interpretations, and encouraged me to 
examine the data through multiple lenses (e.g. the perspective of different stakeholders within the organisation). Finally, in line with Smith, McGannon, and Williams (2015), we hope that our research is judged on whether it makes a meaningful contribution to the field of sport psychology. We aim to show that this study deepens our knowledge and understanding of how professional football cultures influence youth player psychological development.

\section{Ethical considerations}

Ethnographic researchers have highlighted some of the ethical challenges that arise as a result of using ethnographic research methods (Atkinson \& Hammersley, 1994; Brewer, 2000). For example, declaration of research intent, informed consent, and ensuring participant confidentiality are some of the specific challenges for those occupying the position of insider practitioner-researcher. In this study, ethical approval was sought from the relevant University ethics board, and the concept of relational ethics (Ellis, 2007) was considered. The basic premise of relational ethics is that ethical decisions are made within the context of the researcher's relationship with the participant/s (Pollard, 2015). Confidentiality was assured for all individuals within the study as no real names were included, and no information that may lead to the identification of any individual has been used (Brewer, 2000). However, occupying a dual role as a practitioner-researcher within the organisation raised ambiguity regarding the organisation's anonymity, as it may be possible for readers to identify the organisation of study via other means. Although the issue of confidentiality was not raised by the participating organisation, we decided that all information would be anonymized as far as possible, and I understood my responsibility to act in the best interests of the participants at all times. More specifically, I strived to act in a humane manner that aligned with the respect and connectedness that I had developed for those in the organisation (Ellis, 2007), whilst also adhering to my role as a sport psychology researcher (Guillemin \& Gillam, 2004). For example, we considered the participants circumstances, and the potential 
implications of the published data on the organisation, and those at the centre of each narrative. As a result of this, I ensured that the research objectives were made clear to the participants, and I consulted with stakeholders (players and support staff) at different stages of the study (member reflections).

\section{Methodological Reflections}

The occupation of a dual role as an insider practitioner-researcher within Burrington City FC presented a number of challenges. Firstly, I had to manage the time consuming and often conflicting roles of a sport psychology practitioner, and a doctoral researcher. For example, Burrington City FC placed a clear focus on my responsibility to provide psychological support to the youth players. They argued that this was the role that would have a direct and 'immediate' impact on the performance of the players. Consequently, I felt that my role as a researcher was overlooked. In an attempt to overcome this challenge, I reminded the participants of the nature of the study and the research objectives at appropriate stages of the data collection. Secondly, being embedded within Burrington City FC for a longitudinal period meant that I had developed deep connections with, and an emotional tie to some of the individuals within the organisation. Therefore, I found it challenging to ensure that I took a step back from the organisation and explored the data from different lenses. It was through continual reflection and discussions with the research team members that I learnt to manage my positioning on the insider vs outsider continuum (Linbeck, 2001). Each of these challenges demonstrate the importance of appropriate support networks (e.g. peers, critical friends, supervisory support) in questioning, challenging, and ultimately supporting practitioner-researchers during data collection and beyond. 


\section{Results and Discussion}

What follows are a series of three separate, but interrelated narratives that aim to illuminate the daily experiences of academy footballers within one professional football club over a 3-year time period of practitioner-researcher engagement. These narratives are connected in that they all explore the influence of the professional football culture on the identity, development, and/or the consequent behavior of a youth player contracted to Burrington City FC.

\section{'This lad hasn't got what it takes'}

Burrington City FC is renowned for giving young players a chance at senior level. The following narrative explores the experiences of a second year scholar (Nathan) during his transition from the academy to the $1^{\text {st }}$ team environment. Nathan was the stand out player for the U18 age group, and as a result of the $1^{\text {st }}$ team's recent results and performances he had been granted his first ever senior $\left(1^{\text {st }}\right.$ team $)$ start for Burrington City FC.

It didn't go to plan. Nathan was substituted at half time after making a mistake that led to the opposition scoring. He was replaced by an experienced professional, nearly twice his age.

On the Monday morning, Nathan reported to the training ground along with the rest of the $1^{\text {st }}$ team squad. Ryan had called off training, instead they were going to watch the DVD from the weekend's game. Nathan took some hefty criticism during the DVD session, afterwards he left the video room head down. Two days later Nathan approached me, he mentioned what had happened in the DVD room, how embarrassed he was by the criticism he received, and how humiliated he felt. Nathan suggested that he trained worse than ever before today, his confidence was shattered, and he was terrified of making a mistake.

He didn't start the next game, or the game after, and the week after that he was dropped from the squad completely. Nathan hadn't played a game of football in nearly a month, and was 
struggling to understand whether this was a punishment for his mistake, or if it was because he wasn't needed anymore. In an individual support session with Nathan he commented, "Everyone thinks it's all this cause your now with the $1^{\text {st }}$ team, the coaches say it's such an amazing experience and how good it is for your career. But the truth is, I'm not playing any games. I get that I made the mistake, but they did not even give me time to make up for it, they brought me off at half time and I've not had a chance since. If they don't think I'm good enough they should just tell me, I'd accept that. But I'm in no man's land right now'. Nathan felt rejected. He went on to explain that his transition to the $1^{\text {st }}$ team environment was not only hindering his footballing development; it was ruining his relationship with the other players in his own age group... "The lads don't sit with me anymore, they always give me the 'Ohh your too big time (important) for us now', or 'shouldn't you sit with the pros'. I never asked for any of this, and they don't seem to get that. The $1^{\text {st }}$ team don't socialize with me, they think I'm a kid, and now the U18s aren't the same with me. I'm not wanted by any age group, I wish I could just go back to the U18s and be normal like the rest of them". It was clear that Nathan was affected by the comments of the others in his age group. Nathan's experiences continued in this manner, and over the next couple of months he was in and out of the $1^{\text {st }}$ team squad. Although he was still training with the $1^{\text {st }}$ team he had been playing some games back with the U18 age group. I sat with Nathan each week to discuss his experiences, his negativity was overwhelming. Nathan could no longer see any positives in the situation he found himself in. He was experiencing a number of psychological stressors, such as low self-belief, isolation, a dip in form, and career transition. Eventually, Ryan and Paul had decided that Nathan would be better off transitioning back to the U18s full time. His reputation was tarnished amongst the staff, and he now carried the label "that lad hasn't got what it takes". 


\section{Analysis}

As a result of Nathan's transition to the $1^{\text {st }}$ team, and eventually back down to the U18's again, he encountered a range of deep and negative emotions that resulted in him questioning his identity within Burrington City FC. The transition from youth to senior level has been highlighted within sport psychology as one that may pose a number of psychological challenges for the athlete to overcome, inclusive of the threat to an individual's identity (Cacija, 2008; Morris et al., 2016; Stambulova, Pehrson, \& Olsson, 2017). Pummel, Harwood, and Lavallee (2008) argued that the commitment and sacrifice required by athletes during the transition from youth to senior level might lead to narrowing of identity development which could have adverse effects on their well-being later. Nathan's movement to the $1^{\text {st }}$ team was unpredicted, involuntary, and as a consequence of the environment that he found himself within. The cultural discourse used by staff at Burrington City FC about, and towards Nathan, demonstrated their perceptions on the psychological characteristics (e.g. resilience, toughness, leadership, masculinity) that youth players need in order to be successful. Given the cultural characteristics of professional football (e.g., working class traditions, short-term contracts, and punishments for failure), it is suggested that the challenges individuals face during the transition from youth to senior level within this particular social context may be greater than in some other sports (Nesti, 2012). Although Nathan had not yet completed his scholarship, the story he constructed about moving up to the $1^{\text {st }}$ team environment was signified by a lack of social support, and losing his sense of self-worth.

It has been suggested by Nesti and Littlewood (2011) that if a player is to successfully navigate their way through the volatile, and ruthless football culture, they must possess a clear sense of self, and be flexible to respond to the situations that they are exposed to. The professional football culture had a significant and negative impact on Nathan's youth 
to senior transition. For example, coaches were ruthless when criticizing his performance in the video room, and did not grant him a second opportunity to showcase his ability. The cultural narratives and discourses surrounding 'the right kind of a character' acted as confirmation that he was not yet equipped with the psychological attributes to succeed at $1^{\text {st }}$ team level (Blodgett, Schinke, McGannon, \& Fisher, 2015). Unable to align his personal experiences with the dominant narrative Nathan's grew isolated within the organization, and his performance level and self-confidence dropped.

\section{Here today, gone tomorrow: The experience of being sent on loan}

Since the replacement of reserve teams with the U23 age group in football academies, it has become increasingly common for clubs to loan out players either before, or once they attain a professional contract. The aim of this is to expose young individuals to senior football, and explore whether they are ready for the transition from academy football to the so-called 'men's' game. Burrington City FC sent a number of U18 players on loan to local clubs for the final few months of each season. The following story describes a second year scholar's (Connor) loan experience, how he made sense of this experience. Connor signed for the club when he was 10 years old, and based on my own observations, and discussions with other stakeholders at Burrington City FC he was a confident, well liked and professional individual who had good relationships with both the players and coaches.

Connor was called into the U18 manager's office before the scholars were dismissed. Tony (U18 manager) and Harry (U18 assistant manager) informed him that he was going on a 3month loan to Shackleton Town FC until the end of the football season. Connor was further informed that his loan would begin the next day. However, as his loan club was non-league (semi-professional), he would still be based at Burrington City FC on the days that he did not train with Shackleton Town. In the first instance Connor didn't respond well, he couldn't 
understand why he had been sent out on loan, and why he had been given less than a day's notice. In an individual support session, Connor commented, "I play for the 23 s nearly every week, that's where I'll be next season if I get a pro. So shouldn't I be judged on how well I play for them, not some dodgy non-league outfit?". I asked him to go away and think further about the situation that he found himself in, and how he could turn it into a positive. A couple of days later he returned to the club, with a more optimistic outlook on what lay ahead... "I spoke to my dad about it last night, he said it's a good opportunity, they already know I've got the talent, it's just proving myself physically. The U18s games are too easy for me now, and I don't always start for the U23s so I'll take it as it comes, and show em what I've got'". In his first game, Connor did exactly that and was rewarded with man of the match. On the Monday morning, he reported to Burrington City FC. He walked tall, his shoulders broad; Connor was full of energy, and enthusiastic to talk about his first game. In an individual support session, he spoke about how welcoming the players were, and the positive praise he received from the manager. Connor had enjoyed the game and spoke as though Shackleton Town FC now meant something to him. Before he left he asked if I knew why he wasn't involved in the U23 squad for their game that afternoon, but before I had chance to answer he spoke again "It's probably because they want me to rest up after Saturday, maybe they thought the physical side of the game would take it out of me". Connor then left the room and high fived one of the other scholars in the gym.

Despite Connor's 'man of the match' winning performance in his first game for Shackleton Town FC, he failed to start any of their next three games. In addition to this, he had not been a part of any of the U23 squads since his loan spell began. Concerned about what the staff at Burrington City's thoughts were, Connor approached Shackleton Town FC's manager to better understand why he had lost his starting position. He was informed that the club's other right back; an old experienced professional had threatened to leave if "a young kid" started 
in his position. The Shackleton Town FC manager explained to Connor that unless this player had a 'howler' (very poor game) Connor would not be granted a start. Connor was angry, he decided to speak to Tony and explain the situation he found himself in. Tony's response only served to increase the anger further "That's men's football for you, it's a good learning experience, you've got to wait for your chance, and then take it'. Connor didn't agree with this, although he didn't dare say that to the manager. He believed that the writing was on the wall, his time at Burrington City FC was coming to an end, and without game time he couldn't influence their decision. He continued "the other lads laugh at me; they think it's a joke that I'm not starting. The other day Bruiser (youth team scholar) threw all my kit in the pool before training, when I asked him why, he said, "well you won't be needing it much longer". This is my career, and I've only got 3 weeks left. If I get released I will be fuming, no one has even been to watch me, and the U23s gaffer (manager) ignores me. This isn't teaching me a lesson, or helping me learn the game. I come here training and give 100\%, I go and train with Shackleton town FC and do the same, but when it gets to the weekend no one cares. I doubt they would even be bothered if I didn't turn up". In my consequent meetings with Connor, we spoke very little about Burrington City FC and his loan experience. He mentioned a potential move to Scotland or America to continue pursuing his dream of becoming a professional footballer. His focus was no longer on Burrington City FC, and by his own admission he was becoming more isolated from both his teammates and the rest of the organisation. His body language had changed, he was slumped, he looked worn out, and carried himself as though he had the weight of the world on his shoulders. A week later, an injury to one of the $1^{\text {st }}$ team players opened the door for him to start the last two U23 games of the season. Although lacking in motivation, Connor noted that this was a nice way to finish, and looking back on his experiences over the last 8 years he didn't want his time at the club to end on a sour note. 
Decision day arrived, the boys gathered in the changing rooms waiting to be called to their fate. This was one of the biggest days of their lives; the last 10 years had all built up to this. Today was the day that they would either achieve their dream and be given a professional contract, or the day their world would come crashing down. The atmosphere in all areas of the club was different. The players were quiet, nobody joked, and it was tense. The staff spoke about this being the worst day of the season, seeing the lads you have worked with for a number of years leave the club in tears, their hopes and dreams crushed was not easy. Connor was second to be told the news, and he was one of three players in his age group to be offered a professional contract. He now had a decision to make. Did he re-identify with the club, and spend the next 12 months fighting for an extension to his contract despite the organisational challenges that he had faced since being sent on loan, or did he leave, and explore his options elsewhere.

\section{Analysis}

Given the time that Connor had spent as a part of Burrington City FC, I believed that the club had a long standing and deep meaning to his self-concept (Kelman, 1958). Over his 8-year involvement with the club, Burrington City FC had grown to have a significant impact on how Connor thought about, evaluated, and perceived himself (Baumeister, 1999). Subsequently, it was evident that Connor had developed his identity within the dominant narratives surrounding professional sport (Douglas \& Carless, 2009). This was demonstrated in an individual support session about his contract when he commented, "football is all I have ever known, it is all I want to do". Given his tie with Burrington City FC over a significant period of his life, and based on his self-stories we suggest that Connor was relying on a selfidentity constructed within the dominant narratives of this cultural context (Smith \& McGannon, 2017). As a result of this, the experience of a career transition posed a significant threat to his sense of self. In an attempt to cope with the transition, Connor started to look for 
ways in which he could identify with his new club (Shackleton Town FC). Connor began to emphasise the importance of other avenues (e.g. university, other clubs); he spoke about his time at Burrington City FC in the past tense, as though he believed it was over. This alternative discourse might demonstrate that he was exploring his possibilities where to realise his football career path outside this club (McGannon et al., 2012; Smith \& Sparkes, 2009).

Those individuals who are enrolled on a youth scholarship within a professional football club have not yet secured a professional contract, and therefore have very little control over their career development both on a short-term and long-term basis (Roderick, 2006). Parker (1995) suggested that football managers hold all power over their players, and often use the short-term nature of contracts to scare players into listening to any instructions that are given. When individuals fail to align their experiences with culturally dominant and desirable identity positions, they may experience isolation, loneliness, and a lack of selfbelief (Mitchell et al., 2014). Nesti and Littlewood (2011) supported this suggestion, and noted that prior to attaining a professional contract individuals may engage in a range of measures to regain control of their fate, and deal with the feelings of existential anxiety. Balancing these tensions, and dealing with some of the other challenges that occur within the professional football culture may have a detrimental effect on the identity formation and development of a youth player. The lack of social support, and 'banter' (Parker, 1995) directed at or about individuals within the professional football club may also serve to increase the impact of culture on youth player experiences. This is an example of the hegemonic masculinity scripts that young players use to construct their identities within narrow cultural ideas of what it means to be a 'real man' (Smith \& Sparkes, 2009). Gearing (1999) would suggest that this is not uncommon within professional football clubs, where those who hold positions of power and influence use intimidating methods of communication 
to highlight who is no longer valuable within the organization (Parker, 1995). Collinson (1988) supported this, and noted that the brutal jokes and direct comments may signify rejection from the organization. Despite being subjected to discourses that threatened the athletic identities that youth athletes have constructed, the cultural environment also generally expects the players to mask over their true feelings and put on a brave face (Gilbourne \& Richardson, 2006). This illustrates how athletes need to continually perform an athletic identity, which aligns with notions of mental toughness and resilience (Schinke et al., 2016). Youth players may behave, or act in a certain way to fit in with the football narrative, and discourse as opposed to being authentic to their own values and beliefs (Tibbert, Andersen, \& Morris, 2015).

Finally, being offered a contract demonstrated how quickly fate can change in professional football. Nesti (2012) supported this, and noted that players often experience a number of positive and negative emotions during a season. Connor had experienced extremes of emotion over a period of only three months. The challenges that he faced were both personal, and interpersonal, and had influenced his personal and professional development and identity (Richardson et al., 2004).

\section{Power and influence: "You may as well go and sit in the stands mate"}

At Burrington City FC it is common practice for first, and second year scholars to be involved in the U23 squad during the football season. Primarily, this is for the coaches to attain an understanding of those players who they believe will be capable of playing for the $1^{\text {st }}$ team in the future. Generally, the U23 fixtures are scheduled for a Monday, as this provides fringe first team players and talented U18 players with the opportunity to attain extra game time without interrupting the weekend schedule. At Burrington City FC, the players who were involved in the U23 squad would be informed by text following the $1^{\text {st }}$ 
team match on a Saturday. The following story describes an event that occurred between a second year scholar (Josh), and the U23 manager (Aiden) prior to kick off.

Monday morning arrived, and those players who were not involved in the U23 squad reported for training. However, all of the second years were absent. They had each received a text from Aiden, and were in the squad for the U23 game. Josh, and the rest of the second year scholars were asked to report to the match stadium at 11.30am for a 1.00pm kick off. It is club policy that staff, and U18 players watch all U23 home games. Therefore, half an hour before kickoff, I set off from the training ground to head to the stadium with Alex, the youth team sports scientist. The players were out on the pitch warming up, but as I entered the stands to take a seat I saw Josh sat there, head in his hands. "Josh, what you doing up there?" I asked. From looking at his body language, I assumed he was ill. Josh quickly moved his hands, sat upright and responded "Come up here a min and I'll explain”. As I got closer to him, I noticed that his face was a burning red; he spoke quietly to prevent anyone else from hearing. "I can't believe what Aiden's just done, this place calls itself a football club, pfft" Josh was one of the quieter members of the group, but he spoke with anger and passion. He explained that he arrived at the ground as usual, and the squad had watched a pre-match video (DVD of the oppositions last game) in the club lounge before entering the changing rooms. It was here that his ordeal began. As the players changed into their shorts and socks it became apparent that there was one player too many. The U23 captain (Baldy) counted the players, there were 19. Match day squads should be made up of no more than 18, and therefore one player was going to miss out. As Aiden entered the changing room, some of the more confident, older boys led by Baldy informed Aiden of his mistake. Josh noted that the players were laughing and made a rumbling noise as Aiden looked at each of the boys. In front of everyone, Aiden's eyes fixated on Josh, "Josh, you may as well go and sit in the stands mate! There's no point you being in here if you're not in the squad anymore”. Josh 
was left to pack away his boots to the sound of laughter and cheering from the other players. He stated that he had been sat in the stands ever since. As I was talking to Josh one of the head coaches, Jim turned up. He shouted over to Josh, "OI, I thought you were in the squad", Josh replied, "No, Aiden got the numbers wrong”. Jim didn't comment, he just turned his head and continued his conversation. Josh moved to sit with the rest of the U18 players. He never received an apology from Aiden, and the event was not mentioned again. The next month, Josh was released from Burrington City FC.

\section{Analysis}

Individuals signed to a professional football academy have been described as having to navigate their way through a 'school of tough knocks' (Roderick, 2006). Informing Josh in front of the rest of the players, and as bluntly as he did was a demonstration of the power hierarchy that exists within this culture (Roderick, 2006), and influenced his self-identity. This is supported by a social constructionist approach to self-identity, which centralizes the influence of language in the construction of identity. This language clearly depicted whether an individual was accepted, or rejected from the organization. In order to present himself as a 'footballer', Josh needed to perform an identity of someone who was not affected by the situation he found himself in. This could be achieved by displaying behaviors that are associated with that role (e.g. Confirmation to those in positions of power, refusal to demonstrate emotion). Josh had no option but to swallow his pride and listen to Aiden's instructions.

The behavior of the other players further served to heighten the negativity of the experience, and had a significant impact on how Josh constructed his identity. In line with the suggestions of Kelly and Waddington (2006), Baldy and the other individuals were highlighting their position within the organisation, and used the situation as a psychological 
test for Josh to see whether he would 'lose his head'. Further to this, such behaviors have been highlighted as the traditional way within professional football for the older players to assess whether younger players would be able to cope with the relentless and brutal $1^{\text {st }}$ team environment (Parker, 1995; Roderick, 2006). Professional football clubs are described by Gearing (1999) as total institutions, and therefore the other players in the age group may have behaved in the way they did as a result of their own experiences and socialization (Goffman, 1959). However, the implications of this are concerning, in that they may prevent the healthy psychological transition from adolescence to adulthood (Gearing, 1999). In line with the previous two vignettes, Josh had developed a narrow identity narrative that had been constructed within the social context of Burrington City FC. Therefore, when he faced threats to this identity he found it difficult to find alternative narrative resources that could have helped him in sustaining psychological well-being and navigating his way through these challenges. However, we suggest that being excluded, or pushed out from a particular social group may have a significant influence on a person's self-belief, and more importantly their perception of 'who they are' (Brougton \& Neyer, 2001; Sparkes, 1998). Moments such as those experienced by Josh often have a visible impact on an individual's identity, development, and consequent behavior.

Josh was left questioning his self-worth and role within the organisation. He attempted to find an explanation for the situation. However, those who Josh identified with (manger and players) had demonstrated a lack of care towards his thoughts and feelings. This was a critical moment for Josh, and invoked emotions of anger and rejection, demonstrated when I spoke to him in the stands. For Josh, this narrative was a demonstration that he was not accepted at the club (Tibbert et al., 2015). As noted in the previous analysis, de-selection is one of the most commonly reported stressors within professional football (Finn \& McKenna, 2010; Nesti \& Littlewood, 2011; Nesti et al., 2012), and therefore Josh needed to 
appraise the situation and figure out how he would cope going forward. Tibbert et al. (2015) suggested that the only way to be successful would be to embrace the cultural norms and traditions of the club. Josh's experience occurred only a small period before his contract was terminated, and therefore it could be suggested that his experience on this day served as an indicator for what his future held with Burrington City FC.

\section{General Discussion}

We explored player identity as a socio-cultural construction, and illustrated ways in which the dominant cultural narratives/ discourses shape how players understand themselves. Much of the previous research exploring the identity of young athletes (e.g., Gordon \& Lavallee, 2011; Mitchell et al., 2014; Nesti \& Littlewood, 2011; Pummell, Harwood, \& Lavallee, 2008) has used single semi-structured interviews, and relied on retrospective recall for the data collection. This is limited in that the researcher has not observed the individual within the culture they exist, nor had the chance to develop a trusting relationship with them to the same extent as can be achieved when using participant observation. Further to this, a range of data collection methods (observation, field notes, and informal interviews) allowed for a more in-depth understanding of the psychological challenges faced by youth players, resulting in the conclusion that youth players tend to construct their identities, and see their future possibilities solely within the professional football context. This is concerning given the high number of players who will eventually be released. Our suggestion supports previous findings (e.g. Mitchell et al., 2015; Morris et al., 2016) and highlights the need for appropriate sport psychology support to be delivered at youth levels. Methodologically, this study contributes a longitudinal perspective, where I was positioned within the professional football club, and therefore understood the participants prior to, during, and following the events that they were exposed to. The use of ethnography as a research method allowed us to 
attain a deeper understanding of the impact of the professional football culture on the identity development, and consequent behaviors of youth players than has been attained previously.

From the findings that emerged we suggest that despite considerable changes in professional football over recent years (e.g., introduction of the EPPP, global growth, increasing finances), the traditional masculine culture of professional football dominated in the club studied. This culture was demonstrated through the everyday interactions of individuals (Maitland et al., 2015) e.g displays of authority, banter, isolation of individuals, language. In 2012, the Premier League introduced the EPPP as a new youth development framework. The EPPP provided guidance on all aspects of practice, and formalized the delivery of psychological support. However, the findings from this study regarding the professional football culture supported those of Cushion and Jones (2006) who explored coaching practice, and Roderick (2006) who explored the lived experiences of youth apprentices. More specifically, the authoritarian management style, demonstration of power, dominance, and control, and punishments for not adhering to orders were all dominant cultural features that influenced the identity and development of youth players. In particular, it was the behaviour of coaches employed within Burrington City FC that aligned with these cultural features. Thus, we have more confidence in confirming this understanding. Despite research conducted by Cushion, Roderick, and others (e.g. Gearing, 1999; Parker, 1995) suggesting that this is not beneficial for player development, the introduction of the EPPP appeared to have little to no impact on changing the beliefs and behaviours of these individuals. In summary, the EPPP does not appear to have addressed what it set out to do. There are a number of potential reasons to explain this, based on both my observations, and previous literature.

Firstly, a number of the coaches employed at Burrington City FC had progressed through the club's youth system before either having a successful playing career or being 
released. It was suggested by Gearing (1999) that professional football clubs are total institutions (closed social systems that require permission to enter and leave (Goffman, 1957), and that the members within it are often socialized into a certain way of thinking and acting that is in line with the dominant beliefs and values of the organisation. Having been involved in professional football for a significant proportion of their lives, it may be suggested that the coaches have developed hegemonic beliefs that are reluctant to change. In turn, these individuals act as key socialising agents. In addition to this, the coaches also want to survive within this social context, and therefore most need to embody the cultural norms and demonstrate successful performance outcomes. The final explanation is a lack of understanding of sports psychology topics, and its value in youth player development. Pain and Harwood (2004) who noted that coaches were reluctant to integrate sports psychology within their clubs, due to a perceived lack of importance, and lack of understanding of topics that fall outside the general coaching domain, support this suggestion.

Our study extends the use of CSP as a theoretical approach to exploring culture in an organizational setting (e.g., Tibbert et al., 2014). Although identity has been explored previously using athletic identity and Erikson's (1968) identity framework (Brown \& Potrac, 2009; Mitchell et al., 2016) CSP as a theoretical framework has not been used to help us understand player identity development within the cultural context of professional football. In line with the CSP perspective, we explored identity as a fluid concept that is performed in particular ways depending on the cultural context that an individual exists (Schinke et al., 2016). However, the findings from this study indicate that the professional football culture, which is all encompassing and offers limited identity-related resources at both club, and cultural level is detrimental to the psychological development of youth players. This supports previous work such as Tibbert et al., (2015) who conducted a longitudinal case study of a youth footballer within the specific sport subculture, and found that in order to be successful 
at the club the participant needed to embrace the norms and traditions of the hypermasculine football culture. The manner in which individuals are encouraged to 'act' to be labelled with the tag 'footballer' may not be coherent with their more authentic sense of self, thoughts, feelings, attitudes, and beliefs. Therefore, when an individual is faced with a psychological challenge they might not have the resources to be able to successfully navigate their way through challenging experiences.

\section{Applied implications}

If granted the opportunity, future sports psychology delivery within professional football may include an initial period of observation to explore the best approach to applied practice. More specifically, we suggest that future sports psychology practice within professional football may best be delivered at an organisational level with the primary focus of creating an optimal environment for psychological development, and in turn performance (e.g. challenging, and supporting players in equal measure). Research has supported this, and suggested that professional football is a performance-driven, high-pressure environment that places a short-term focus on achieving immediate results (Nesti, 2010). Chandler et al. (2016) noted that this level of pressure often leads to conflict, and it can be the sports psychologist who is allocated the organisational role of managing the consequences (e.g. re-building relationships, establishing roles and responsibilities). In line with this, it is believed that by creating an optimal development environment, players may have a smoother development journey within professional football clubs.

However, without an understanding of the sub-cultural features and characteristics of an organisational culture, a sports psychologist may not be effective in this role. The results and discussion sections of this paper demonstrated the need for applied sports psychology practitioners to be aware of, and able to deliver organisational psychology support. In line 
with this, there would be great value in introducing a focus on organisational culture within professional training and education routes. More specifically, this may include education on the realities of working in professional and elite sport organisations (Eubank et al. 2014). At undergraduate and postgraduate levels, this might incorporate sociological literature from those with experience in elite sport contexts, such as Parker (1995), and Roderick (2006). This would be beneficial in helping students to better understand the social context of sporting environments that they one day may work within. During professional training, this may be delivered through a series of workshops presented by guest speakers from within a specific sport culture, and placements where practitioners are given the opportunity to observe and practice in these settings. In addition to greater education through practitioner education and training, it is suggested that trainee's supervisors may also play a significant role in increasing their student's awareness of organisational psychology, particularly if they possess appropriate theoretical knowledge (e.g., the work of Fletcher and Wagstaff (2009) on organisational psychology in elite sport, and more recently Eubank and colleagues (2014) on understanding high performance sport environments). The sports psychologist may face a number of challenges when attempting this in practice (e.g., stakeholder attitudes and beliefs). Without the support of key stakeholders, we suggest that the sports psychologist may find it close to impossible to create a positive culture change. Secondly, influencing a football club on an organisational level may be a difficult and time-consuming process for any sport psychologist, and may not be realistic given the short-term nature of many contracts, and lack of focus placed on the discipline by many clubs. Furthermore, the suspicion demonstrated by professional football clubs towards academics, and addition of a new member of staff attempting to change tradition may not be well received. 


\section{Limitations}

Sport researchers (e.g. Hayhurst, 2016; Sparkes \& Smith, 2014) identify generalisability as an issue that cannot be ignored in qualitative research. However, Lewis and Ritchie (2003) argued that we should not sacrifice such a rich and detailed understanding of human beings within a social context based on traditional notions of generalisability, rather we should explore alternative forms of generalisation (e.g. representational, naturalistic). In this study, the findings resonate with my own experiences of the professional football culture and its impact on close family members. In addition to this, the findings are similar to previous studies (e.g. Parker, 1996; Roderick, 2006), and thus are likely to be generalisable to individuals embedded in a similar cultural and discursive contexts. Each researcher highlighted the masculine, authoritarian, and challenging culture that exists for staff and players within professional football. Finally, we do not know where those players who were unsuccessful in progressing through the academy are now, and therefore we don't really understand the long term consequences of being immersed in this world to their personal development, identity and well-being. This could be addressed by studies that look into former player's life trajectories a number of years after they were released.

\section{Conclusions}

Through the current study, we sought to extend understandings of the cultural experiences of elite youth footballers over three competitive playing seasons, and explore how these experiences influenced player identity development and behaviour. From a social constructionist view the narrative/discursive context of the football club encouraged the players to develop self-stories focused on single-minded dedication to sport, which is likely to narrow their life design and have detrimental effects on their well-being if they get deselected. Further studies conducted within other professional football clubs since the 
introduction of the EPPP would help us to better understand whether the findings from this study lie in isolation, or if they are generalizable across clubs in the UK (and Europe). In addition to this, it would deepen our understanding of the conditioning effect of long-term exposure to professional football environments (Gearing, 1999). The results of studies such as this may serve to inform the future development of the EPPP framework, and consequently influence the daily working practices of professional football clubs. Finally, a holistic and longitudinal examination of the challenges that are faced by players within the specific development phases in isolation (e.g., FP, YDP, PDP, Senior level) may allow for a more indepth understanding of how player challenges change as a function of age, and stage of development. This would build upon the research findings from this study. To date, only Nesti (2012), and Nesti (2013) have used case studies to explore the experiences of elite senior level professional footballers. A clearer understanding of the challenges that players face across their football careers may inform more effective sports psychology practice. 


\section{References}

Anderson, G., \& Miller, R. M. (2010). Inclusive masculilnity theory and the gendered politics of men's rugby. Journal of Gender Studies , 19, 249-261.

Atkinson, P., \& Hammersley, M. (1994). Ethnography and participant observation. In: Handbook of qualitative research. Thousand Oaks, California: Sage, 248-261.

Baumeister, R. F. (1999). The nature and structure of the self: An overview. In R. Baumeister (Ed.), The self in social psychology . Philadelphia, PA: Psychology Press (Taylor \& Francis), $1-20$.

Blodgett, A. T., Schinke, R. J., McGannon, K. R., \& Fisher, L. A. (2015). Cultural sport psychology research: conceptions, evolutions, and forecasts. International Review of Sport and Exercise Psychology, 8(1), 24-43.

Bogdan, R., \& Biklen, S. K. (1982). Qualitative research for education: an introduction to theory and methods. Boston, MA: Allyn and Bacon.

Brewer, J. D. (2000). Ethnography. Buckingham: Open University Press.

Brewer, B., Van Raalte, J., \& Linder, D. (1993). Athletic Identity: Hercules' muscles of Achilles' heel? International Journal of Sports psychology, 24, 237-254.

Broughton, E., \& Neyer, M. (2001). Advising and Counselling Student Athletes. New Directions for Student Services, 93, 47-53.

Brown, G., \& Potrac, P. (2009). 'You've not made the grade, son': de-selection and identity disruption in elite level youth football. Soccer \& Society, 143-159. 
Bruner, M. W., Munroe-Chandler, K. J., \& Spink, K. S. (2008). Entry into elite sport: A preliminary investigation into the transition experiences of rookie athletes. Journal of Applied Sport Psychology, 20(2), 236-252.

Čačija, G, (2007). Qualitative study of the career transition from junior to senior sport in Swedish basketball (C-thesis in Sport Psychology 41-60 p). School of Social and Health Sciences, Halmstad University.

Chandler, C., Eubank, M. R., Nesti, M. S., \& Tod, D. (2016). Personal qualities of effective Sports psychologists: Coping with organisational demands in high performance sport. International Journal of Sports psychology, 47(4).

Chavez, C. (2008). Conceptualizing from the inside: Advantages, complications, and demands on insider positionality. The Qualitative Report, 13(3), 474-494.

Chryssochoou, X. (2003). Studying identity in social psychology: Some thoughts on the definition of identity and its relation to action. Journal of Language and Politics, 2(2), 225241.

Collinson, D. (1988). 'Engineering humour': Masculinity, joking and conflict in shop-floor relations. Organisation studies, 9(2), 181-199

Cornbleth, C. (1990). Curriculum in context. London and New York: Falmer.

Cushion, C. \& Jones, R. L. (2006). Power, Discourse, and Symbolic Violence in Professional Youth Soccer: A Case of Albion Football Club. Sociology of Sport, 23(2), 142-161.

De Rond, M. (2008). The last amateurs; to hell and back with the Cambridge Boat Race crew. London: Icon Books. 
Douglas, K., \& Carless, D. (2009). Abandoning the performance narrative: Two women's stories of transition from professional sport. Journal of applied sport psychology, 21(2), 213230.

Dowling, G. (1993). Developing your company image into a corporate asset. Long Range Planning, 26(2), 101-109.

Ellis, C. (2007). Telling Secrets, Revealing Lives. Relational Ethics in Research with Intimate Others. Qualitative Inquiry, 13(1), 3-29.

Erikson, E. (1968). Identity, Youth and Crisis. New York: Norton.

Eubank, M., Nesti, M. \& Cruickshank, A. (2014). Understanding high performance sport environments: Impact for the professional training and supervision of Sports psychologists. Sport and Exercise Psychology Review, 10, 30-36.

Fletcher, D. \& Wagstaff, C. (2009). Organisational psychology in elite sport: Its emergence, application, and future. Psychology of sport and exercise, 10(4), 427-434.

Friesen, A. \& Orlick, T. (2010). A Qualitative Analysis of Holistic Sports psychology Consultants' Professional Philosophies. The Sports psychologist, 24, 227-244.

Gailbraith, P. (2004). “Organisational leadership and chaos theory: Let's be careful”, Journal of Educational Administration, 42(1), 9-28.

Gearing, B. (1999). Narratives of Identity among former professional footballers in the United Kingdom. Journal of Aging Studies, 13, 43-58.

Gilbourne, D. \& Richardson, D. (2006). Tales from the field: Personal reflections on the provision of psychological support in professional soccer. Psychology of Sport and Exercise, 7(3), 325-337. 
Goffman, E., (1959). The presentation of self in everyday life. New York: Doubledau Anchor Books.

Gordon, S., \& Lavallee, D. (2011) Career transitions. In: Morris, T., Terry, P. (ed.). The New Sport and Exercise Psychology Companion, Morgantown, WV, USA: Fitness Information Technology, pp. 567-582.

Greene, M. J. (2014). On the inside looking in: Methodological insights and challenges in conducting qualitative insider research. The qualitative report, 19(29), 1-13.

Guillemin, M. \& Gillam, L. (2004). Ethics, reflexivity, and "ethically important moments" in research. Qualitative Inquiry, 10(2), 261-280.

Hatch, J. M., \& Schultz, M. (1997). Relations between organizational culture, identity and image. European Journal of marketing, 31(5/6), 356-365.

Hayhurst, L. M. (2016). Sport for development and peace: a call for transnational, multisited, postcolonial feminist research. Qualitative research in sport, exercise and health, 8(5), 424-443.

Javadi, M. \& Zarea, M. (2016). Understanding Thematic Analysis and its Pitfalls. Journal of Client Care, 1(1), 33-39.

Kahan, D. (1999). Coaching behaviour: A review of the systematic observation research literature. Applied Research in Coaching and Athletics Annual, 14, 17-58.

Kelly, S. \& Waddington, I. (2006). Abuse, intimidation and violence as aspects of managerial control in professional soccer in Britain and Ireland. International Journal for the Sociology of Sport, 41(2), 147-164.

Kelman, H. (1958). Compliance, identification, and internalization: Three processes of attitude change. Journal of Conflict Resolution, 2, 51-60. 
Knapp, B.A. (2012). Smash Mouth Football: Identity Development and Maintenance on a Women's Tackle Football Team. Journal of Sport and Social Issues, 38(1), 51-74.

Kolar, K., Ahmad, F., Chan, L., \& Erickson, P.G. (2015). Timeline Mapping in Qualitative Interviews: A Study of Resilience with Marginalized Groups. International Journal of Qualitative Methods, 14(3), 13-32.

Krane, V. \& Baird, S. (2005). Using Ethnography in Applied Sports psychology. Journal of Applied Sports psychology, 17(2), 87-107.

Lewis, J., \& Ritchie, J. (2003). Generalising from qualitative research. Qualitative research practice: A guide for social science students and researchers, 2, 347-362.

Lindbeck, A., \& Snower, D. (2001). Insiders versus Outsiders. The Journal of Economic Perspectives, 15(1), 165-188.

Lofland, J. \& Lofland, L. H. (1984). Analyzing social settings. Belmont, California: Wadsworth Publishing Company.

Maharaj, N. (2016). Using field notes to facilitate critical reflection. Reflective Practice, 17(2), 114-124.

Maitland, A., Hills, L. A., \& Rhind, D. J. (2015). Organisational culture in sport-A systematic review. Sport Management Review, 18(4), 501-516.

McGannon, K.R., Curtin, K., Schinke, R.J., \& Schweinbenz, A.N. (2012). (De) Constructing Paula Radcliffe: Exploring media representations of elite running, pregnancy, and motherhood through cultural sport psychology. Psychology of Sport and Exercise, 13(6), 820829. 
McGannon, K.R., \& Smith, B. (2015). Centralizing culture in cultural sport psychology research: The potential of narrative inquiry and discursive psychology. Psychology of Sport \& Exercise, 17, 19-87.

McGillivray, D., Fearn, R., \& McIntosh, A. (2005). Caught up in and by the beautiful game: A case study of Scottish professional footballers, Journal of Sport and Social Issues, 29(1), $102-123$.

Mills, A., Butt, J., Maynard, I., \& Harwood, C. (2012). Identifying factors perceived to influence the development of elite youth football academy players. Journal of sports sciences, 30(15), 1593-1604.

Mitchell, T.O., Nesti. M., Richardson, D., Midgley, A.W., Eubank, M., \& Littlewood, M. (2014). Exploring athletic identity in elite-level English youth football: a cross-sectional approach. Journal of Sports Sciences, 32(13), 1294-1299.

Morill, C., \& Fine, A. (1997). Ethnographic Contributions to Organizational Sociology. Sociological Methods \& Research, 25(4), 424-451.

Morris, R., Tod, D., \& Oliver, E. (2016). An Investigation into Stakeholders' Perceptions of the Youth-to-Senior Transition in Professional Soccer in the United Kingdom. Journal of Applied Sport Psychology, 28, 375-391.

Morrow, S.L. (2005). Quality and Trustworthiness in Qualitative Research in Counselling Psychology. Journal of Counselling Psychology, 52(2), 250-260.

Nesti, M. S. (2012). Sporting recommendations for spiritual encounters: Delivering sports psychology inside the English Premier League. Physical Culture and Sport, Studies and Research, 14-23. 
Nesti, M. \& Littlewood, M. (2011). Psychological preparation and development of players in premiership football: practical and theoretical perspectives. In: T. Reilly, A. Williams \& B. Drust, eds. International Research in Sciences and Soccer. London: Routledge.

Nesti, M., Littlewood, M., O'Halloran, L., Eubank, M., \& Richardson, D. (2012). Critical Moments in Elite Premiership Football: Who Do You Think You Are? Physical Culture and Sport. Studies and Research. 56, 23-32.

Ortlipp, M. (2008). Keeping and using reflective journals in the qualitative research process. The qualitative report, 13(4), 695-705.

Pain, M. \& Harwood, C. (2004). Knowledge and perceptions of sports psychology within English soccer. Journal of Sport Sciences, 22, 813-826

Parker, A. (1995). Great Expectations: Grimness or Glamour? The Football Apprentice in the 1990s. The Sport Historian, 107-126.

Patton, M. Q. (2005). Qualitative research. John Wiley \& Sons, Ltd.

Pollard, C.L. (2015). What is the Right Thing to Do: Use of a Relational Ethic Framework to Guide Clinical Decision-Making. International Journal of Caring Sciences, 8(2), 362.

Reeves, C.W., Nicholls, A.R., \& McKenna, J. (2009). Stressors and coping strategies amont early and middle adolescent premier league academy soccer players: Differences according to age. Journal of Applied Sport Psychology, 21(1), 21-48.

Richardson, L. (2000). New writing practices in qualitative research. Sociology of Sport Journal, 17, 335-352.

Roderick, M., (2006). The work of professional football: A labour of love?. London : Routledge 
Ryba, T.V., \& Wright, H.K. (2010). Sport psychology and the cultural turn: Notes toward cultural praxis. The cultural turn in sport psychology, 3-28.

Schinke, R.J., McGannon, KR., Parham, W.D., \& Lane, A.M. (2012). Towards Cultural Praxis and Cultural Sensitivity: Strategies for Self-Reflexive Sport Psychology Practice. Quest, 64(1), 34-46.

Schinke, R., Papaioannou, A.G., \& Schack, T. (2016). Sport psychology in emerging countries: An introduction. International Journal of Sport and Exercise Psychology, 14(2), 103-109.

Sheridan, J., Chamberlain, K., \& Dupius, A. (2011). Timelining: visualizing experience. Qualitative Research, 11(5), 552-569.

Smith, B. (2013). Disability, sport, and men's narratives of health: A qualitative study. Health Psychology, 32(1), 110-119.

Smith, B., \& McGannon, K.R. (2017). Developing rigor in qualitative research: problems and opportunities within sport and exercise psychology. International Review of Sport and Exercise Psychology, 1-22

Smith, B., McGannon, K. R., \& Williams, T. (2015). Ethnographic creative non-fiction: Exploring the what's, why's and how's. In L. Purdy \& G.Molner (Eds.), Ethnographies in sport and exercise, 59-73. London: Routlegde.

Smith, B. \& Sparkes, A. C. (2009). Narrative inquiry in sport and exercise psychology: What is it, and why might we do it? Psychology of Sport and Exercise, 10(1), 1-11.

Sparkes, A. C. (1998). Athletic identity: An Achilles' heel to the survival of self. Qualitative health research, 8(5), 644-664. 
Stambulova, N., Alfermann, D., Statler, T., \& Cote, J. (2009). ISSP position stand: career development and transition of athletes. International Journal of Sport and Exercise Psychology, 7, 395-412.

Stambulova, N., Pehrson, S., Olssson, K. (2017). Phases in the junior-to-senior transition of Swedish ice hockey players: From a conceptual framework to an empirical mode. International Journal of Sports Science and Coaching, 12(2), 231-244.

Tibbert, S., Andersen, M., \& Morris, T. (2015). What a difference a "Mentally Toughening" year makes: the acculturation of a rookie. Psychology of Sport and Exercise, 17, 68-78.

Tierney, K. J. (2002). The Field Turns Fifty: Social Change and the Practice of Disaster Field Work. In: Methods of Disaster Research. Phildelphia: Xlibris, 349-374

Tracy, S. J. (2010). Qualitative Quality: Eight “Big-Tent” Criteria for Excellent Qualitative Research, Qualitative Enquiry, 16(10), 837-851.

Weiss, R. S. (1994). Learning from strangers: The art and method of qualitative interviewing. New York: The Free Press.

Wittgenstein, L. (1953). Philosophical investigations. Oxford: Blackwell.

Wylleman, P., Alfermann, D., \& Lavallee, D. (2004) Career transitions in sport: European perspectives, Psychology of Sport and Exercise, 5(1),7-20. 